\title{
Industria del automóvil y desarrollo económico regional: la experiencia de Navarra (c. 1955-1980)
}

\author{
Car industry and regional economic development: \\ The case of Navarre (c. 1955-1980)
}

\author{
JOSEBA DE LA TORRE CAMPO \\ Universidad Pública de Navarra
}

\begin{abstract}
RESUMEN
La experiencia de Navarra durante 1955-1980 constituye un ejemplo significativo de éxito en el desarrollo económico regional a través de la creación de un enclave industrial basado en la automoción. Para que la fábrica de coches se instalase en Landaben fue necesaria una acción institucional decidida a influir en el crecimiento económico y una iniciativa privada activa ante los estímulos del mercado nacional. Incentivos fiscales y ayudas públicas, capacidad empresarial para la innovación tecnológica y trabajadores cualificados impulsaron una red de proveedores de la planta de ensamblaje. Sin embargo, AUTHI fue golpeada con gravedad por la crisis económica de los setenta. Adquirida por el consorcio del INI, la gestión de SEAT sentó unas bases saneadas para convertirla en una planta exportadora de automóviles. Este análisis de caso, por tanto, ilustra algunas de las características de la industrialización española y del desarrollo regional durante el franquismo.
\end{abstract}

PALABRAS CLAVE: : Industria del automóvil, Desarrollo regional, Historia empresarial, Navarra, España Códigos JEL: H3, L6, N6, N8

\section{ABSTRACT}

The case of Navarre during 1955-1980 is a significant example of successful regional economic development through the creation of an industrial area based on car production. In order to enable settlement of the car factory in Landaben, a decisive institutional action enabling economic growth, together with the initiatives from the private sector as a reaction to national market's encouragements, were necessary. Fiscal incentives and public subsidies, business capacity for technological innovation and qualified workers let to the creation of a network of supplying companies providing spare parts for the manufacturing and assembly plant. However, the AUTHI car company was severely beaten by the international economic crisis of the 1970s. Purchased by the INI consortium, SEAT's managers set up the grounds that would transform Landaben into an automobile exporter plant. This case analysis shows therefore some of the features of the Spanish industrialization and regional development under General Franco's regime.

KEY WORDS: Car Industry, Regional

Development, Business History, Navarre, Spain

JEL Codes: $H 3, L 6, N 6, N 8$ 


\section{Introducción ${ }^{1}$}

U no de los fenómenos que mejor ejemplifica el proceso de industrialización de Europa occidental en la segunda mitad del siglo XX ha sido el desarrollo de la industria de la automoción y sus auxiliares. Numerosas regiones económicas encontraron en esta especialización la palanca de la riqueza durante los años cincuenta y sesenta, y experimentaron las transformaciones del sistema productivo en la dura crisis de los setenta ${ }^{2}$. En plena efervescencia del debate sobre los riesgos de deslocalización empresarial que en apariencia entraña una Unión Europea ampliada hacia el este, las enseñanzas del análisis histórico de algunos ejemplos de desarrollo regional ligado a la automoción pueden resultar de interés. En el caso de Navarra, el automóvil proyecta las luces y algunas sombras de ese proceso. Entre 1995 y 2002 este sector concentró un 18 por 100 de la población activa industrial y alrededor de un 50 por 100 de las exportaciones de la región. Para algunos, la viabilidad económica y social del territorio está fuertemente supeditada a la marcha de esta industria. Sin embargo, los estudios sobre la relevancia macroeconómica de la planta del consorcio Volkswagen en Landaben matizan esa visión pesimista. El tejido fabril surgido en torno al automóvil abastece en una escala notable a otros distritos industriales del motor fuera de Navarra y las exportaciones de componentes de la industria auxiliar suponen ya un 20 por 100 del total de las ventas internacionales de esta comunidad ${ }^{3}$. La historia económica y empresarial puede contribuir a despejar algunas incertidumbres y a precisar algunos rasgos esenciales del debate sobre los factores que determinan la localización industrial. La intrahistoria de este proceso de cambio económico es poco conocida y sus raíces son anteriores al hito cronológico de 1966, cuando se puso en funcionamiento una planta de ensamblaje de automóviles en las cercanías de Pamplona. En buena medida, su trayectoria ha corrido en paralelo al proceso por el que el sector del automóvil ha pasado a ocupar uno de los lugares centrales en la explicación de la industrialización española desde los años cincuenta y, sobre todo, sesenta ${ }^{4}$; pero el ejemplo navarro encierra algunas peculiaridades que condicionaron el desarrollo regional y que deben ser exploradas.

[Fecha de recepción del original, diciembre de 2006. Versión definitiva, mayo de 2007]

1 Versiones preliminares de este trabajo fueron presentadas en el VII Congreso de la Asociación de Historia Económica (Zaragoza, 2001) y Cátedra de la Fundación Eduardo Barreiros para el Estudio de la Industria de la Automoción en España (Madrid, 2002). Los comentarios de los colegas que participaron en ellos y de los cuatro evaluadores anónimos de Investigaciones de Historia Económica han enriquecido y mejorado este trabajo. Desde aquí mi agradecimiento.

2 Algunos ejemplos en Rodwin y Sazanami (1991). También, Crafts y Toniolo (1996), pp. $23-24$ y 32.

3 Aláez y Erro (2006), pp. 378-379. Varios análisis de caso en García Ruiz (2003).

4 Véase Catalan (2000) y García Ruiz (2001). Para el conjunto industrial, Llopis y Fernández (1998). 
En este artículo se indagan, en primer lugar, los orígenes del sector a partir de los proyectos empresariales de los años cincuenta para instalar en Navarra una fábrica de automóviles, el surgimiento en paralelo de industrias auxiliares que comenzaron a abastecer a las plantas españolas $-\mathrm{y}$, en particular, las vinculadas al grupo empresarial Huarte - y, además, el modo en que se resolvió la formación técnica de los trabajadores que, procedentes del campo, fueron empleados en las fábricas. A continuación, se aborda el nacimiento de la empresa de ensamblaje Automóviles de Turismo Hispano-Ingleses, S.A. (AUTHI), al hilo de los cambios registrados en los mercados desde los primeros años sesenta y de las ayudas públicas recibidas en la modalidad navarra de planificación indicativa. Finalmente, se analizan los efectos de la crisis económica de los setenta y el apoyo político a un sector en peligro al poco de nacer. La oportunidad que brindaba la industria automovilística para transformar de modo acelerado las bases económicas en la España de Franco ha de ser contemplada también como una posibilidad de hacer negocio para empresas que supieron situarse ventajosamente entre el Estado y el mercado $^{5}$.

Son conocidas las razones por las que la política nacionalista del Instituto Nacional de Industria en el sector del automóvil abogó por la cooperación tecnológica foránea y sus resultados ${ }^{6}$. No obstante, ese análisis debe completarse desde la perspectiva de las estrategias de las grandes empresas francesas o italianas para participar en ese proyecto. Después de 1945, en los países atrasados se generalizó la idea de que la industria automovilística constituía una oportunidad para acortar rápidamente la brecha que les separaba de los países industriales y abastecer al mercado local. Manufacturar vehículos permitiría el aprendizaje industrial de todo un país; además, resultaba atractivo para las empresas transnacionales. Instalarse en esas economías no sólo suponía aprovechar la ocasión de actuar en mercados nacientes, sino también una respuesta racional ante la amenaza para el negocio exportador derivada del alza de aranceles en países como Brasil, Japón, Portugal o España. Se ha demostrado que esas barreras a la importación fueron las que impulsaron la estrategia de Renault o Citroën para lanzar el montaje de coches en el extranjero, por más que quedara sometida a serias dificultades financieras y técnicas ${ }^{7}$. Y en ese proceso la iniciativa privada autóctona - empresarios y banqueros- participó de manera

5 Es decir, la versión hispana del "capitalismo de compadrazgo", un esquema de actuación empresarial para hacer negocios, adaptándose a las restricciones institucionales y a los incentivos gubernamentales: subvenciones públicas, acceso preferente al crédito y a las licencias de importación, y baja presión fiscal. Véanse Krugman (1999), pp. 50 y 113, y Valdaliso (2002), pp. 586-590.

6 San Román (1999).

7 Loubet (1996), pp. 189-195. Un planteamiento global del sector en la posguerra, en Nadal y Tafunell (1992), pp. 218-225. 
activa. Los logros en esta fase embrionaria del sector explicarían una parte del éxito, ya en la década de los setenta, de la producción eficiente de vehículos para el mercado internacional ${ }^{8}$.

\section{Los orígenes y los factores de localización}

A mediados de los años cincuenta, Navarra seguía constituyendo un ejemplo de síntesis entre una economía de base agraria y otra con cierto grado de diversificación en manufacturas y servicios, si bien aún no alcanzaba los parámetros típicos que permiten identificar una estructura económica en trance de industrialización. Al contrario, los indicadores demográficos insistían en revelar una sangría poblacional que cada año expulsaba factor trabajo ante la insuficiente creación de empleo ${ }^{9}$. Ese fenómeno se agudizó al recuperarse el ritmo de mecanización de las tareas agrícolas anterior a la Guerra Civil, provocando un aumento del desempleo y la consiguiente preocupación de las autoridades regionales y del sector privado. Fue entonces cuando capitales de origen autóctono comenzaron a movilizarse tratando de aprovechar algunas de las posibilidades de negocio que emergían tras la larga noche autárquica, y cuando las instituciones públicas locales intentaron atraer la instalación de fábricas mediante incentivos fiscales.

En plena autarquía el foro de empresarios y profesionales que se reunía alrededor del Consejo Económico Sindical de Navarra (CESN) —un embrionario gabinete de estudios del sindicato vertical-, pronosticaba, en mayo de 1955, acerca de las industrias con mayor futuro en la región. Visto retrospectivamente, su propuesta no pudo ser más lúcida: Navarra debía especializarse en "los mil derivados de la electrónica" — de los aparatos de televisión a los motores- y, sobre todo, "en empresa de gran volumen", la apuesta sería "la fabricación de automóviles", pues "no cabe duda que hay lugar para varias más en el mercado nacional y especialísimamente para la fabricación del coche realmente popular, al alcance de la gran masa de consumidores", que "es evidentemente la de más porvenir"10. Conocedores de los mercados y de las tecnologías, consideraban "necesario el concurso o asociación con una empresa extranjera" para "contribuir con toda su

8 Sobre las capacidades limitadas por los requerimientos de "contenido local", García Ruiz (2001), pp. 137138, y Catalan (2000), pp. 134-137. Entre la literatura de los factores de localización, Hayter (2004).

9 De la Torre y García-Zúñiga (2003), De la Torre (2005) y Garrués (2006).

10 Primer Consejo Económico Sindical de Navarra (1954-55), Ponencia sobre Incremento Industrial Provincial, original mecanografiado, colección particular. 
experiencia, métodos, patentes e incluso maquinaria y técnicos"11. Al fin y al cabo, ésa estaba siendo la práctica empresarial de alguno de estos asesores del CESN, visitando plantas europeas y norteamericanas, negociando licencias tecnológicas y desarrollando líneas de producción novedosas para la España de la época ${ }^{12}$. Como en otras partes, existía el convencimiento institucional y empresarial de que producir vehículos en serie era una de las mejores opciones para la industrialización del territorio. Los proyectos iniciales de lograr una planta de ensamblaje de coches acabaron frustrándose, pero simultáneamente se forjó una manufactura auxiliar y se comenzó a cualificar la mano de obra para acceder a la producción en masa de bienes duraderos. Más allá de la dimensión local, el análisis de esta fase de arranque ofrece una imagen cabal del sector automovilístico en la España anterior a 1960 .

\subsection{Proyectos abortados y autarquía}

En agosto de 1955 Pedro González-Bueno solicitaba al Ministerio de Industria autorización para instalar en Navarra una planta de "fabricación y montaje de automóviles Citroën de $2 \mathrm{CV}$, en sus modelos berlina y furgoneta". Era el primer paso para constituir la sociedad Citroën Hispania. Desde ese momento y hasta finales de 1956, el presidente de la Diputación de Navarra, Miguel Gortari ${ }^{13}$, llevó personalmente las gestiones para lograr que la firma francesa aceptase venir a la región. La correspondencia mantenida con el promotor, las autoridades del Ministerio de Industria, la subdelegación en la provincia, el ministro de Trabajo y los representantes de la empresa gala en Madrid retrata las prácticas de compadrazgo entre lo público y lo privado y las rigideces de un mercado todavía sometido en buena medida a la disciplina autárquica. Es notorio que González-Bueno —que había sido ministro de Organización y Acción Sindical y miembro del Consejo de Estado-, pertenecía al grupo de falangistas que se consolidó en la élite económica durante el primer franquismo ${ }^{14}$.

11 Así, "durante mucho tiempo tendríamos todo el mercado nacional en exclusiva”. Primer Consejo Económico Sindical de Navarra (1954-55), Ponencia sobre Incremento Industrial Provincial, original mecanografiado, colección particular.

12 Se trataba de ingenieros, economistas e inversores ligados a las principales empresas y negocios de la época. Véase De la Torre (2005).

13 Fue subsecretario de Industria y Comercio en el Gobierno de Lerroux en 1934 y procurador en Cortes desde 1942.

14 Ingeniero de Caminos, su cartera de negocios se centró en el sector eléctrico. Presidió el Consejo de Administración de Citroën Hispania. Jerez (1982), pp. 136, 154 y 172. 
Citroën pretendía alcanzar una producción de 10.000 coches facturando 450 millones de pesetas anuales. Un tercio de la cadena de montaje se importaría de Francia, emplearía de 400 a 500 obreros, y se confiaba que en un plazo de seis años "la fabricación se hará íntegramente en talleres nacionales". Además de aportar la marca, patentes, asistencia técnica y procedimientos de fabricación, la licencia incluía la libre exportación de vehículos y piezas. La Diputación navarra decidió entrar en la puja para que la fábrica se instalase en Alsasua —nudo ferroviario entre Guipúzcoa y la Meseta - y se puso en contacto con los ministros de Industria, Joaquín Planell, y Trabajo, José Antonio Girón, “devoto amigo” de Gortari. La respuesta del primero fue dar largas al asunto arguyendo que "la industria auxiliar del automóvil está ya sobrecargada por los numerosos pedidos de la industria del motor", con métodos de fabricación deficientes ("las fábricas actuales trabajan todavía en un solo turno [...] cosa antieconómica dado el alto precio de las máquinas") y sin maquinaria moderna, lo que alejaba la posibilidad de producir en serie; en consecuencia, el precio de los vehículos resultaba excesivo. Pero no sólo era un problema de oferta; las autoridades de Industria estimaban que el mercado ya estaba suficientemente cubierto. Así, en noviembre, la petición fue denegada "hasta comprobar el posterior desarrollo en España tanto de esta industria como del mercado de automóviles"15. Para entonces, el presidente del Consejo de Administración, barón de Roure, y los ingenieros de Citroën habían visitado las posibles ubicaciones de la planta en Navarra - junto a la opción de Alsasua, se evaluó enclavarla en las inmediaciones de Pamplona- y habían negociado con el vicepresidente foral ventajas en el acceso a suelo industrial y algunas exenciones fiscales. Pese al rechazo inicial, los contactos siguieron en Madrid. El gobernador civil, el alcalde de Pamplona y el vicepresidente foral se entrevistaron con el ministro de Industria y, siguiendo el consejo de Girón, hicieron gestiones para "visitar al Caudillo".

De forma algo sorprendente, el Consejo de Ministros autorizó en la primavera de 1956 a la sede parisina de Citroën para que participase en un 45 por 100 del capital de su filial española, siempre que aquél llegase a los 100 millones —cifra que más que duplicaba la previsión inicial-y que el 80 por 100 se dedicase a inversiones fijas. El 20 de junio la Dirección General de Industria resolvía favorablemente el expediente para su instalación en Alsasua, pese a lo cual a la diputación no se le ocultaba el riesgo de que "se monte en otro lugar". Y es que esa repentina viabilidad del proyecto suscitó que varias ciudades se ofreciesen para acoger las instalaciones, entre otras Valladolid. El vicepresidente de la Diputación se presentó en las oficinas

15 En contra de lo previsto, "FASA no ha conseguido aún nacionalizar la fabricación del motor Renault 4-4". Archivo Administrativo de Navarra (AAN, en adelante), Hacienda, Caja 2871/1; y BOE, 229 (18/08/1955) y $317(13 / 11 / 1955)$. 
de la casa Citroën en Madrid, sin cita ni planes previos. Sólo recibió buenas palabras. El proyecto estaba en el aire, como se deducía de la conversación privada que, a los pocos días, mantuvo Gortari con el promotor y repentinamente elusivo González-Bueno tras una sesión en las Cortes: más que las ayudas fiscales ofrecidas, serían determinantes la conexión ferroviaria, las posibilidades de la industria auxiliar, el suministro de agua y energía eléctrica y "la preparación rápida de mano de obra especialista". En suma, un agregado de factores de localización tan amplio que permitía proporcionar razones fundadas para una respuesta tanto afirmativa como negativa, por lo que se trataría en definitiva de una decisión fundamentalmente política. El BOE publicaba la resolución en agosto, ambas administraciones se felicitaban ${ }^{16} \mathrm{y}$, ya en septiembre, las autoridades francesas del ministerio de Economía y Finanzas daban por hecho que la fábrica se construiría finalmente en Pamplona $^{17}$. Pero el proyecto voló a Galicia, al puerto de Vigo y su Zona Franca ${ }^{18}$. El compadrazgo político navarro fue más débil que el gallego y esta práctica acabó reforzando los factores puramente económicos de localización. No sólo en forma de ventajas fiscales, sino también en el acceso privilegiado a los cupos de divisas y a las licencias de importación de la cadena de montaje para Vigo entre 1958 y $1959^{19}$.

El Consejo de Administración de Citroën había dado al traste con los planes de la Diputación, por más que instalarse en Navarra garantizase un nudo ferroviario muy próximo a la frontera francesa y la conexión con el mercado interior. Además, la región era excedentaria en energía eléctrica y los otros dos factores - mano de obra e industria auxiliar- no parece que fuesen inferiores: desde mediados de los años cuarenta, Navarra fue pionera en la puesta en marcha de escuelas de formación profesional, con especial énfasis en las ramas metálica y mecánica, y la cercanía al núcleo fabril de Guipúzcoa la conectaba con una red de talleres experimentados en la máquina-herramienta.

Al menos, la Liga Guipuzcoana de Productores apoyó el recurso de alzada de la Diputación navarra ante Industria al estimar que las pequeñas firmas de esa provincia estaban en condiciones de asistir con eficacia a la planta de ensamblaje: "El reparto de tareas entre los talleres existentes [...] es una modalidad a la que están habituadas muchas de nuestras empresas [tanto por tradición como por] el extraordinario desarrollo de nuestra industria [desde el final de la Guerra Civil]". Los 29.000 productores de 1930 eran 81.000 en 1955, "agotando la mano de obra autóctona y

16 AAN, Hacienda, Caja 2871/1; y BOE, 229 (16/08/1956).

17 Archives du Ministère d'Économie et Finances (AMEF, en adelante), Trèsor, B. 43848. Informes del consejero comercial, Madrid (15/09/1956).

18 Sobre la trayectoria de Citroën Galicia, véase Carmona (2003).

19 Los suministros franceses para la fábrica de Vigo, en AMEF, Trèsor, B. 43848. 
provocando [...] una marcada inmigración de otras provincias", en un negocio que había transformado en poco más de treinta años poblaciones como Eibar, Placencia, Elgoibar, Mondragón, Hernani y el puerto de Pasajes, que habían pasado de producir casi exclusivamente armas a fabricar máquinas de coser y de escribir, bicicletas, motocicletas, máquinas-herramientas, etc. Según la Liga, "todo ello refleja el espíritu de iniciativa y netamente industrial del guipuzcoano [...] todo cuanto tiene del negocio lo invierte en ampliaciones y mejoras de su taller". Además, existían ya firmas ligadas a la automoción -Aparicio Hermanos, Anma, Ayra, Durex Co., Madaya, Alfa, Unión Cerrajera (metalmecánicas) y Neumáticos Michelin-que precisaban "buscar consumidores para los excedentes de producción actuales" ${ }^{20}$. El panorama descrito era radicalmente distinto del que se deducía de la obsesión ministerial por las insuficiencias de la iniciativa privada para afrontar nuevos retos y abrir mercados. De hecho, desde los primeros años cincuenta, los observadores extranjeros venían insistiendo en que la importación masiva de bienes de equipo era clave para que la industria española recuperase los niveles de preguerra, y esto hacía de España un mercado con gran potencial para la Europa industrializada y los emprendedores locales ${ }^{21}$.

De este modo, cobra sentido el segundo proyecto de fábrica de automóviles de turismo y vehículos industriales que se intentó establecer en la región, en 1958, con la peculiaridad de que, en este caso, se trataba de una iniciativa de un empresario vizcaíno, José Estancona Acha. Tras no ser autorizada su propuesta de desarrollar una cadena de montaje de turismos y furgonetas cien por cien nacional, auxiliada por una red de pequeños talleres y fábricas de accesorios en el distrito fabril del Duranguesado y en el entorno de la ría de Bilbao, intentó ubicarla al sur de Navarra. Sin patentes ni tecnología extranjera y al servicio del proyecto autárquico ${ }^{22}$, la apuesta de Estancona fue una historia fracasada que, no obstante, sintetiza las dificultades del sector mientras perdurase la política industrial autárquica. Las causas argüidas por el Ministerio de Industria no eran otras que la "situación actual y futuro mercado consumidor"; "la escasez de productos semi-manufacturados, especialmente productos siderúrgicos", y también de material no férrico y aceros especiales; y unos mercados ya cubiertos por las instalaciones autorizadas por la Administración ${ }^{23}$. En la práctica, la lógica ministerial coincidía con la de las empresas privadas que impug-

AAN, Hacienda, Caja 2871/1.

Archives du Ministère des Affaires Étrangères (AMAE, en adelante), Europe: Espagne, 148, 199, 246,333 y 334; e informes de la embajada francesa en Madrid (1955-1966).

22 Archivo General de la Administración (AGA, en adelante), Industria, Caja 6386, exps. 47.686 y 49.311 ; y AAN, Hacienda, Caja 2871/2.

23 AGA, Industria, Caja 6386, exps. 47.686 y 49.311; y AAN, Hacienda, Caja 2871/2. Sobre el rechazo del INI a fomentar el sector desde los talleres existentes en el país, véase San Román (1999), pp. 251 y ss. 
naron el proyecto vizcaíno en cuanto se publicó en el BOE, haciendo valer su capacidad de presión para frenar la competencia. Mientras la Asociación Española de Fabricantes de Máquinas Herramientas alegaba si la maquinaria se podría adquirir en España, la ensambladora de turismos Renault en Valladolid requería que se impusiesen condiciones iguales a las exigidas a FASA. Industrias del Motor (Imosa) de Vitoria —fabricante de vehículos industriales_, Defensa Antigás de Segovia, y Autonacional —fabricante del Biscúter-Voisin- de Barcelona, insistían en la "suficiencia de producción y escasa productividad de la industria auxiliar"24.

Estancona replicó señalando que el país importaba vehículos — "un desembolso considerable de divisas, siempre necesarias para otros artículos que no producimos"-, existía una demanda insatisfecha de profesionales y colegiados —un sorteo de cinco mil coches de importación había resultado escaso- y una demora media de seis meses a un año en la entrega del turismo adquirido. Además, las autorizaciones a Citroën e Hispano-Diesel, con patente extranjera, provocarían elevadas cargas en forma de royalties, mientras "existen en España industriales que quieren poner la enseña de la Patria en un sector que ha sido siempre de dominio exclusivo extranjero"25. En suma, un discurso propio de algunos empresarios que habían interiorizado el clásico de la autarquía industrial y se habían sometido a sus reglas. Y no sólo en el diseño de la propuesta, sino en la estrategia de buscar los más altos apoyos institucionales: Estancona llegó a exhibir tres de sus vehículos en el palacio de El Pardo ante el mismo Franco, que le animó a proseguir en el empeño ${ }^{26}$.

En 1958 se archivó definitivamente el expediente. Sin embargo, ninguno de los informes de Industria hizo referencia a que el proyecto fuese inviable en términos tecnológicos. Las contradicciones del Ministerio radicaban en que las mismas razones para rechazar esa iniciativa - estrangulamientos de oferta y demanda- no se aplicaron a otras peticiones. Por tanto, es posible que la intervención pública regulando ese mercado estuviese ligada a propósitos no explicitados en la documentación y ligados, por ejemplo, a la apuesta del INI por hacer viable el proyecto de la Sociedad Española de Automóviles de Turismo (SEAT) como gran productor nacional. Tanto el ejemplo de Citroën como este último muestran que, junto a los criterios tria", Madrid, 23-5-1956.

26 AAN, Hacienda, Caja 2871/2. Y añadía: "cabe preguntar si con ese criterio no habremos hecho mal en instalar en España industrias que antes eran de exclusiva extranjera, como son [...] radios, neveras, aspiradoras, máquinas herramientas e incluso motores de aviación con creación de la estructura de aparato y otros muchos artículos que nunca se fabricaron en España [y que] algún día fueron nuevos en el mercado". AGA, Industria, exp. 49.311. 
de eficiencia económica, en la localización de las fábricas de automóviles se contemplaron también los intereses de quienes tenían mayor capacidad de presión sobre los organismos de decisión pública. En suma, el esquema explicativo que muestra las posibles interferencias públicas sobre la iniciativa privada es bastante más complejo que el antagonismo Estado versus mercado. Al fin y al cabo, fueron los empresarios privados que ya habían logrado ocupar posiciones adelantadas en ese mercado los que exigieron al Ministerio de Industria barreras de entrada a posibles competidores.

\subsection{Las industrias auxiliares se adelantan a la planta de ensamblaje}

Una de las vías para someter a prueba los argumentos de las autoridades de Industria frenando la alternativa de los fabricantes puramente nacionales consiste en comprobar si eran reales o no las deficiencias atribuidas a las industrias auxiliares de la automoción antes de los años sesenta. En un mercado de turismos abastecido vía importaciones - caras y consumidoras de divisas - o con la puesta en marcha entre 1950 y 1956 de seis plantas ensambladoras —todas con licencia y patente extranjera-, se confiaba que en el corto y medio plazo las empresas se abasteciesen de insumos españoles. Esa estrategia esperaba que las plantas de ensamblaje crearan en su entorno, de inmediato, un efecto de arrastre para la inversión en fábricas de accesorios. En ese punto de partida no debe extrañar que aquellas zonas con un nivel industrial previo intentasen aprovechar esas oportunidades de negocio. Si el planteamiento antes citado de la patronal guipuzcoana no era descabellado, tampoco lo era el de Navarra, donde, desde mediados de los años cincuenta, se fundaron talleres y fábricas orientados a satisfacer la demanda de accesorios de la automoción para el mercado español. Aquí, primero surgió un núcleo de industrias auxiliares y, más tarde, ello facilitó el arranque de una gran fábrica de automóviles a finales de los sesenta.

Las razones básicas de ese proceso debemos encontrarlas en una oportunidad de negocio emergente que supieron aprovechar algunos empresarios navarros y que, en lo esencial, se definía por las características que recogía en 1963 un informe del Sindicato Nacional del Metal. La política gubernamental había impulsado un esquema de reserva del mercado doméstico para los productores nacionales al exigir que los insumos fuesen de producción española, al intervenir sobre los precios y al fijar restricciones a la competencia exterior ${ }^{27}$.

\footnotetext{
$27 \quad$ Sindicato Nacional del Metal (1963), pp. 93-95.
} 


\section{CUADRO 1}

INVERSIÓN FUNDACIONAL DE SOCIEDADES NAVARRAS EN INDUSTRIAS, DETALLANDO LOS SECTORES DEL METAL Y AUXILIAR DEL AUTOMÓVIL, 1950-1969

(millones de pesetas de 1959 y porcentajes)

\begin{tabular}{|c|c|c|c|c|c|c|}
\hline \multirow[b]{2}{*}{ Inversión en } & \multicolumn{3}{|c|}{ 1950-1959 } & \multicolumn{3}{|c|}{$1960-1969$} \\
\hline & $\begin{array}{c}\text { Capital } \\
\text { fundacional }\end{array}$ & $\begin{array}{l}\text { Porcentaje } \\
\text { sobre (1) }\end{array}$ & $\begin{array}{l}\text { Porcentaje } \\
\text { sobre (2) }\end{array}$ & $\begin{array}{c}\text { Capital } \\
\text { fundacional }\end{array}$ & $\begin{array}{l}\text { Porcentaje } \\
\text { sobre (1) }\end{array}$ & $\begin{array}{c}\text { Porcentaje } \\
\text { sobre (2) }\end{array}$ \\
\hline Industrias & 795,55 & 100,0 & - & $3.762,15$ & 100,0 & - \\
\hline (2) Industrias metálicas & 288,85 & 36,2 & 100,0 & 861,88 & 22,8 & 100,0 \\
\hline (3) Auxiliares del automóvil & vil 35,81 & 4,4 & 12,1 & 282,74 & 7,5 & 32,7 \\
\hline
\end{tabular}

Fuentes: Registro Mercantil de Navarra (RMN, en adelante), Libros de Sociedades, 1940-1969.

\subsubsection{Capitales autóctonos modestos y entrada de capital transnacional}

A partir del Registro Mercantil hemos reconstruido la trayectoria de la industria automovilística en Navarra. El intervalo de 1950 a 1969 muestra cómo, partiendo de un mercado regional prácticamente virgen, una serie de capitales privados, en su mayoría de modestas dimensiones, comenzaron a invertirse en plantas de accesorios, material eléctrico, talleres de reparación y concesionarios de firmas nacionales y extranjeras, y en colocar esa producción en el mercado doméstico. Pequeños talleres y líneas de especialización de algunas empresas metalúrgicas contribuyeron a este desarrollo, que acabaría fraguando de manera espectacular en torno a 1966, cuando las expectativas suscitadas por la inminente apertura de la planta de Landaben provocaron el redoblamiento de las inversiones.

Un análisis desagregado del proceso inversor en industrias metálicas y en empresas directamente vinculadas a los suministros de automoción revela con mayor exactitud el peso alcanzado por un proceso que marcaría la trayectoria de la industrialización del territorio navarro, y que se desencadenó antes de la década de 1960. En términos absolutos (Cuadro 1), el sector del metal reforzó su protagonismo en ese decenio, al triplicar en pesetas constantes el capital movilizado en los años cincuenta, mientras que en términos relativos el arranque inicial de los derivados del transporte sobre el conjunto de las industrias metálicas se vio confirmado con igual intensidad, hasta significar un tercio del total de esa rama manufacturera ${ }^{28}$. 


\section{CUADRO 2}

GRADO DE CONCENTRACIÓN Y TAMAÑO DE LAS EMPRESAS AUXILIARES DEL AUTOMÓVIL EN NAVARRA, SEGÚN EL CAPITAL FUNDACIONAL, 1950-1969

(millones de pesetas de 1959 y porcentajes)

\begin{tabular}{lcccc}
\hline & Capital & $\begin{array}{c}\text { Porcentajes } \\
\text { sobre el total }\end{array}$ & $\begin{array}{c}\text { Número de } \\
\text { empresas }\end{array}$ & $\begin{array}{c}\text { Capital } \\
\text { por empresa }\end{array}$ \\
\hline $\mathbf{3}$ 40 millones & 69,02 & 22,0 & 1 & 69,02 \\
$\mathbf{2 5 - 4 0}$ millones & 71,19 & 22,0 & 2 & 35,59 \\
$\mathbf{1 5 - 2 5}$ millones & 53,70 & 17,0 & 3 & 17,90 \\
$\mathbf{1 0 - 1 5}$ millones & 38,36 & 12,0 & 3 & 12,78 \\
$\mathbf{5 - 1 0}$ millones & 29,85 & 9,0 & 5 & 5,97 \\
$\mathbf{2 , 5 - 5}$ millones & 24,82 & 8,0 & 7 & 3,54 \\
$\mathbf{1 - 2 , 5}$ millones & 25,12 & 8,0 & 15 & 1,67 \\
$<\mathbf{1}$ millón & 6,46 & 2,0 & 13 & 0,49 \\
\hline Total & $\mathbf{3 1 8 , 5 6}$ & $\mathbf{1 0 0 , 0}$ & $\mathbf{4 9}$ & \\
\hline
\end{tabular}

Fuentes: Las mismas del Cuadro 1.

En suma, anticipándose al estímulo como factor de localización de la planta de ensamblaje, casi medio centenar de empresas comenzaron a fabricar sistemas de frenado, amortiguadores, carrocerías, tubos de escape y silenciosos, cajas de cambios, cigüeñales y asientos, para dar respuesta a la demanda de las fábricas de turismos y otros medios de transporte de fuera de la región, con lo que se estaba generando una trayectoria que facilitaría las economías de aglomeración cuando AUTHI fuese una realidad. No obstante, ese tejido manufacturero, ubicado mayoritariamente en el área de Pamplona, exige ser analizado en su recorrido temporal y organizativo. Que una quinta parte de las empresas reuniera tres cuartas partes del capital inicial -y sólo tres de ellas un 44 por 100- o, a la inversa, que un 80 por 100 de las firmas aportara una cuarta parte de los capitales (Cuadro 2), nos habla de un complejo entramado de grandes y pequeñas plantas de producción, fábricas y talleres, en el que concurrían inversores foráneos y autóctonos en desigual proporción.

El grupo de las mayores empresas del subsector industrial auxiliar del automóvil muestra un negocio repartido entre firmas de origen familiar y otras con capital transnacional atraídas por el "efecto llamada" de la futura ensambladora de turismos que, además, podían servirse de la actividad desplegada por los empresarios locales y de una mano de obra suficientemente adiestrada. Como revela el Cuadro 3 , excepto Imenasa y Urra, fundadas en 1953 y 1957, todas las demás grandes empresas se crearon a partir de 1965. De las tres firmas multinacionales, dos buscaron la cola- 


\section{CUADRO 3}

LAS GRANDES EMPRESAS DE LA INDUSTRIA AUXILIAR DEL AUTOMÓVIL

(millones de pesetas corrientes)

\begin{tabular}{llllcccc}
\hline $\begin{array}{c}\text { Empresas } \\
\text { (Sociedades } \\
\text { Anónimas) }\end{array}$ & Localidad & $\begin{array}{c}\text { Fecha de } \\
\text { creación }\end{array}$ & $\begin{array}{c}\text { Capital } \\
\text { nominal }\end{array}$ & $\begin{array}{c}\text { Capital } \\
\text { desem- } \\
\text { bolsado }\end{array}$ & $\begin{array}{c}\text { Número } \\
\text { de } \\
\text { acciones }\end{array}$ & $\begin{array}{c}\text { Tipo de } \\
\text { grupo }\end{array}$ & $\begin{array}{c}\text { Origen de la } \\
\text { mayoría del } \\
\text { capital }^{*}\end{array}$ \\
\hline Urra Española & Pamplona & $5 / 03 / 57$ & 13,500 & 13,500 & 9 & Familiar & $\mathrm{N}$ \\
Imena & Pamplona & $24 / 12 / 53$ & 10,000 & 10,000 & 7 & Familiar & $\mathrm{N}$ \\
Inmetu & Tudela & $19 / 05 / 65$ & 20,000 & 10,000 & 3 & Familiar & $\mathrm{N} / \mathrm{VIZ}$ \\
Norton & Pamplona & $23 / 08 / 65$ & 30,000 & 30,000 & 3 & Multinac. & USA \\
Talleres Iruña & Pamplona & $22 / 04 / 66$ & 50,000 & 37,500 & 4 & Familiar & $\mathrm{N}$ \\
Bendibérica & Pamplona & $21 / 06 / 66$ & 91,875 & 91,606 & 54 & Multinac. & N/CAT/USA \\
Sunsundegui e Hijos & Alsasua & $30 / 11 / 66$ & 17,000 & 17,000 & 5 & Familiar & $\mathrm{N}$ \\
Magoteaux-Luzuriaga & Urdiain & $23 / 06 / 67$ & 45,000 & 11,250 & 11 & Multinac. & BEL/GUI \\
Navarra de Abrasivos & Carcastillo & $5 / 05 / 69$ & 15,000 & 15,000 & 6 & Sociedad & N/CAT \\
\hline
\end{tabular}

(*) N (Navarra), CAT (Cataluña), VIZ (Vizcaya), GUI (Guipúzcoa), USA (Estados Unidos), BEL (Bélgica).

Fuentes: Las mismas del Cuadro 1.

boración de empresarios autóctonos —navarros, guipuzcoanos, vizcaínos y catalanes-, lo que permite intuir una estrategia que combinaba la entrada de nueva tecnología y métodos de producción modernos con un conocimiento directo de los mercados de factores - materias primas y trabajadores -29 . Y conforme se desciende a las 40 empresas de menores dimensiones, los capitales modestos y familiares ilustran la capacidad de respuesta local ante la nueva demanda. Un mercado sometido a serias restricciones institucionales alentó la iniciativa local antes de que se desencadenasen los efectos de los planes de desarrollo. De hecho, las ayudas públicas que ofreció la Diputación de Navarra a las nuevas y viejas industrias, desde abril de 1964, concurrieron para dar coherencia a un proceso impulsado previamente por la iniciativa privada en pleno cambio del ciclo económico. El análisis del principal grupo inversor en las ramas auxiliares del transporte proporciona algunas pistas de interés de la génesis de esa opción de especialización manufacturera de la región.

29 La automoción fue uno de los sectores en los que el flujo inversor vasco recaló en Navarra, con parecida intensidad al de los electrodomésticos y a cierta distancia del metal y la maquinaria. De la Torre (2005), p. 142, Cuadro 8. 


\subsubsection{El Grupo Huarte y el automóvil: un ejemplo de estrategia inversora}

La figura del empresario Félix Huarte Goñi (1896-1971) desborda el ámbito local y constituye uno de los ejemplos paradigmáticos del triunfador del capitalismo español de los dos primeros tercios del siglo XX. Hombre hecho a sí mismo, con una trayectoria como empresario innovador en el ramo de las constructoras y en el de las industrias emergentes de la España de las décadas centrales del siglo XX, perteneció al "núcleo duro" de las sesenta principales fortunas de la gran industria y las finanzas y, en los años finales de su vida, ocupó puestos de responsabilidad política, llegando a presidir la diputación de Navarra ${ }^{30}$. Si en las décadas de 1930 y 1940 consolidó una empresa constructora de nivel nacional —combinando la innovación técnica y la competencia de sus obras con la capacidad para hacerse con los concursos de obras públicas de las instituciones del Estado (universidades, ministerios, hospitales, carreteras y hasta el Valle de los Caídos) — ${ }^{31}$, lo singular es que esa "acumulación originaria de capital" fue dirigida hacia el desarrollo de una serie de industrias que iban a resultar fundamentales en el proceso de cambio de la economía fabril española. La necesidad de bienes intermedios metálicos para la constructora acabó derivando en la puesta en marcha de importantes fábricas vinculadas a la máquina-herramienta y, sobre todo, a la automoción desde mediados de los años cincuenta (Cuadro 4).

A partir de los actos formalizados en el Registro Mercantil de Navarra cabe bosquejar la trayectoria de Félix Huarte como la de un personaje atento y conocedor del mercado, y con los contactos políticos suficientes para tomar el pulso con acierto a los ciclos económicos y fundar un grupo de empresas complejas desde el punto de vista de la capitalización requerida, la tecnología, las prácticas gerenciales o la búsqueda de nuevos socios dentro y fuera del país. La red básica de fábricas auxiliares del automóvil, a la que antes hemos aludido, se creó entre 1953 y 1962 en torno a una veintena de sociedades mercantiles e industriales ${ }^{32}$. Huarte estaría ligado a este proceso a través del antiguo taller mecánico que, desde 1927, abastecía de algunos suministros a su constructora. Éste se convirtió en fábrica en 1945, registrándose cuando se hallaba a pleno rendimiento, en 1953, como Industrias Metálicas de Navarra S.A. (Imenasa). Como se asegura en la documentación manejada, esta firma tuvo un "gran desarrollo, fabricando [...] grúas y carpintería de aluminio con licencias extranjeras", y diversificando pronto la producción hacia "frenos y otros elementos de automóviles".

\footnotetext{
30 Muñoz (1969), p. 478. Su biografía en Paredes (1997).

31 Es de sumo interés la documentación del Archivo Histórico de Félix Huarte (AFH, en adelante) editada por Paredes (1995).

32 Muestra del temprano interés por la industria del transporte fue su ambición de fabricar motocicletas en serie, que abandonó ante el empuje de Vespa, y su presencia en el Consejo de Administración de Imosa. Paredes (1995), pp. 168-170; y García Ruiz (2001).
} 


\section{CUADRO 4}

CAPITAL MOVILIZADO POR EL GRUPO HUARTE SEGÚN SECTORES, 1951-1970

(pesetas de 1959)

\begin{tabular}{lccc}
\hline \multicolumn{1}{c}{ Grupo Huarte } & Capital & $\begin{array}{c}\text { Porcentaje sobre } \\
\text { total del grupo }\end{array}$ & \\
\hline (1) Grupo Industrial & 1.169 .762 .953 & 39,73 & \\
(2) Inmobiliaria y Finanzas & 1.774 .293 .264 & 60,27 & \\
\hline Total & $\mathbf{2 . 9 4 4 . 0 5 6 . 2 1 6}$ & $\mathbf{1 0 0 , 0 0}$ & \\
\hline (1) Grupo Industrial & Capital & Porcentaje sobre & Porcentaje sobre total \\
& & Grupo Industrial & industrias metálicas \\
\hline (a) Química & 69.787 .214 & 5,97 & 43,82 \\
(b) Metalmecánica & 288.810 .018 & 24,69 & 56,18 \\
(c) Auxiliares de Automoción & 370.291 .404 & 31,66 & \\
(d) Papel & 440.874 .317 & 37,69 & \\
\hline Total & $\mathbf{1 . 1 6 9 . 7 6 2 . 9 5 3}$ & $\mathbf{1 0 0 , 0 0}$ & \\
\hline
\end{tabular}

Fuentes: Las mismas del Cuadro 1.

En su órbita se situaron empresas que atendían fabricaciones diversas, como papel y grasas industriales, pero la actividad fundamental se centró en el automóvil; hacia 1959 ya era proveedora de "las principales fábricas españolas", suministrando embragues y direcciones a la Empresa Nacional de Autocamiones (ENASA) y frenos a Nueva Montaña Quijano ${ }^{33}$.

El grueso de las apuestas del grupo industrial estaba ya en juego antes de 1960 (Cuadro 5). Para entonces, junto a un plan de cualificación de los trabajadores para formar oficiales y maestros en las ramas del metal y la mecánica, existían contactos con las multinacionales europeas y norteamericanas, primero en términos de compra de licencias y transferencia tecnológica, y después en calidad de socios financieros. Las manufacturas del metal y del equipamiento de transporte acabaron significando en la época que estudiamos el 56 por 100 del capital movilizado en la industria, aunque sólo el 22 por 100 del conjunto del "imperio Huarte", por el peso decisivo del negocio inmobiliario. Todo ello conducido por un grupo reducido y compacto de personas que configuraban un equipo altamente cualificado para desarrollar la estrategia de crecimiento elegida: el patriarca, sus cuatro hijos 


\section{CUADRO 5}

CRONOLOGÍA DE LOS CAPITALES INVERTIDOS POR EL GRUPO HUARTE EN NAVARRA, 1951-70 (miles de pesetas de 1959 y porcentajes)

\begin{tabular}{lrrrrr}
\hline & $\mathbf{1 9 5 1 - 1 9 5 5}$ & $\mathbf{1 9 5 6 - 1 9 6 0}$ & $\mathbf{1 9 6 1 - 1 9 6 5}$ & $\mathbf{1 9 6 6 - 1 9 7 0}$ & $\mathbf{1 9 5 1 - 1 9 7 0}$ \\
\hline \multicolumn{5}{c}{ Valores absolutos } \\
\hline Capital inicial desembolsado & 39.564 & 77.893 & 6.466 & 2.771 & 126.694 \\
Ampliaciones desembolsadas & 28.571 & 424.817 & 215.726 & 925.713 & 1.594 .827 \\
Liberaciones capital & 5.824 & 99.291 & 214.694 & 347.158 & 666.967 \\
Crédito oficial y obligaciones & 0 & 0 & 173.619 & 381.942 & 555.561 \\
\hline Total & $\mathbf{7 3 . 9 5 9}$ & $\mathbf{6 0 2 . 0 0 1}$ & $\mathbf{6 1 0 . 5 0 5}$ & $\mathbf{1 . 6 5 7 . 5 8 4}$ & $\mathbf{2 . 9 4 4 . 0 4 9}$ \\
\hline & & & Porcentajes & \\
\hline Capital inicial desembolsado & 53,49 & 12,94 & 1,06 & 0,17 & 4,30 \\
Ampliaciones desembolsadas & 38,63 & 70,57 & 35,34 & 55,85 & 54,17 \\
Liberaciones capital & 7,87 & 16,49 & 35,17 & 20,94 & 22,65 \\
Crédito oficial y obligaciones & 0,00 & 0,00 & 28,44 & 23,04 & 18,87 \\
\hline Total & $\mathbf{1 0 0 , 0 0}$ & $\mathbf{1 0 0 , 0 0}$ & $\mathbf{1 0 0 , 0 0}$ & $\mathbf{1 0 0 , 0 0}$ & $\mathbf{1 0 0 , 0 0}$ \\
\hline
\end{tabular}

Fuentes: Las mismas del Cuadro 1.

-Jesús (industrial sin formación académica), Juan (economista), Felipe (ingeniero industrial) y María Josefa ("sin profesión") — y sus parientes políticos y amigos en el accionariado y en la gerencia y asesoría del grupo - Javier Vidal Sario (ingeniero industrial y yerno de Félix), Valentín Erburu (perito industrial), Jesús Echarte (perito industrial), Jesús Aizpún (abogado y cuñado de Felipe) y la familia Malumbres Oteiza (cofundadora de la inmobiliaria) — . Las empresas ligadas al sector de la construcción no sólo concentraron las mayores cantidades de capital, sino que también generaron los beneficios que permitieron financiar la vertiente industrial del grupo y consolidar un poderoso patrimonio familiar a partir de sumas relativamente modestas de capital fundacional ${ }^{34}$. Los cerca de 3.000 millones de pesetas constantes

34 Para gestionar el núcleo inversor familiar se creó H. Beaumont, S.R.C., en 1956, una sociedad patrimonial entre el padre y los cuatro hijos que acabaría concentrando casi un tercio del capital de las empresas del grupo. El fundador aportaba una cartera de valores cuya composición ilumina dos rasgos estratégicos: uno, un peso dominante de valores seguros (electricidad, banca, cemento y construcción); y dos, una apuesta inicial por las industrias metálica, química y papelera. RMN, Hoja 1582. 
(de 1959) inyectados en la economía navarra en apenas dos décadas ponen de manifiesto la acción de un habilidoso conglomerado empresarial creador de valor, que canalizó una porción considerable de sus beneficios hacia nuevos negocios y generó un volumen de empleo y rentas con importantes efectos de arrastre en el desarrollo regional.

La década del desarrollismo más que triplicó, en términos constantes, el ritmo inversor de Huarte, con el auxilio del crédito oficial y las emisiones de obligaciones. Ello fue posible por tratarse de un grupo bien colocado ex ante para responder al fabuloso tirón de la demanda de viviendas, electrodomésticos y turismos, tres de los sectores con mayor dinamismo en la etapa final de la dictadura franquista. Además, Huarte no pretendió rebasar las dimensiones a las que se podía ajustar el empresario español de la época. Fabricar maquinaria, derivados del metal y equipamiento del transporte, y no automóviles completos, fue una apuesta bastante racional de adaptación. Los Huarte eran pragmáticos y entendieron que era mejor diversificar la cartera de negocios, aceptar la compra de tecnología en el extranjero, concentrarse sólo en adiestrar el factor trabajo preciso y confiar en que el crecimiento de la renta y la industrialización impulsarían al alza el consumo de bienes duraderos. Lejos de sus planes quedó erigir una fábrica de automóviles que, además, hubiese requerido unos capitales de similar cuantía a los del conjunto del grupo. Jugárselo todo a una carta no era el estilo de Huarte.

\subsection{Formando trabajadores para el desarrollo regional}

Finalmente, una de las claves del salto hacia adelante en la industrialización de este territorio fue la dotación de capital humano para los requerimientos fabriles. Las instituciones navarras apostaron por la educación profesional desde finales de los años cuarenta y, más aún, en los cincuenta, con el objetivo de conectar la capacitación de especialistas para las nuevas industrias metálicas con la creación de escuelas profesionales en los núcleos de población más notables ${ }^{35}$. En 1955, directivos de empresa e ingenieros industriales, conocedores de primera mano de la realidad de las fábricas, diagnosticaban que la "industrialización" requeriría "de una suficiente masa de mano de obra experta que, desde luego, no existe en la actualidad y que habrá de ser creada en menos de diez años". Había que extender las escuelas de capacitación para

35 Sobre la inversión pública en Formación Profesional, De la Torre y García-Zúñiga (2003), p. 120. Además de la Escuela salesiana de Pamplona, entre 1954 y 1962 se fundaron escuelas privadas en las cabeceras de comarca, subvencionadas por la Diputación, para formar oficiales y maestros en las ramas del Metal, Electrónica y Madera. El Estado promovió una escuela sindical y un instituto laboral. 
oficiales y maestros industriales — los "jefes de taller" —, dado que la escasez de firmas de gran tamaño hacía que buena parte de las plantillas se cualificase, al más puro learning by doing, como "aprendices de taller"36. Antes de la irrupción de los planes de desarrollo, la apuesta por una red básica y propia que formase trabajadores procedentes del éxodo rural había cimentado en Navarra, dando respuesta a las "crecientes dificultades para proveerse de la mano de obra apropiada" en las industrias de mayor intensidad de capital tecnológico.

La muestra del peso que en cada ámbito productivo tenían especialistas, personal no cualificado y aprendices ofrece una panorámica clarificadora (Cuadro 6). En el conjunto industrial, cerca del 40 por 100 de los asalariados presentaba un perfil de capacitación bajo. La naturaleza tecnológica de cada sector configuraba dotaciones de especialistas dispares, destacando la posición de las ramas metálica, papelera y maderera. Desgraciadamente desconocemos en qué grado se transformó esta estructura laboral en las dos décadas postreras. Más aún cuando es probable que la demanda de obreros cualificados fuese superior al número de jóvenes que hubiesen acabado sus estudios en cualquiera de las ramas profesionales, y cuando la enseñanza obligatoria concluía a los catorce años y el aprendizaje a pie de obra era una salida laboral inmediata ${ }^{37}$. Este esquema de análisis encajaría, por tanto, en aquellas industrias intensivas en mano de obra y de bajo nivel tecnológico, y su grado de adaptación disminuiría conforme los requisitos técnicos precisasen de una cualificación relativa mayor ${ }^{38}$.

De nuevo el ejemplo de Imenasa es útil. Esta fábrica rompió con la educación informal y apostó por suplir a la oferta pública. En 1952 creaba su propia escuela para unas 120 plazas de oficiales y maestros ajustadores, fresadores y torneros, "ante la falta de mano de obra especializada" para "el cumplimiento de los compromisos contraídos" 39 . Permaneció abierta hasta 1969, cuando la oferta de Formación Profesional (FP) la hizo innecesaria, dado que la acción institucional continuó impulsando el gasto, creando cuatro escuelas nuevas y haciendo realidad la Escuela de Ingeniería

36 Primer Consejo Económico Sindical de Navarra (1954-55), Ponencias sobre Formación Profesional e Incremento Industrial Provincial, original mecanografiado, colección particular.

37 Según el decreto regulador de la enseñanza profesional (1958), se podía adelantar ese proceso. El período de preaprendizaje se comenzaba a los doce años; el de oficialía a los catorce (tres cursos académicos) y la maestría después. Rey Altuna (1965), p. 53.

38 La primera plantilla de obreros de la factoría de coches se reclutó mediante un mecanismo informal eficaz. Los técnicos recorrieron los talleres de reparación, pintura y estampado de automóviles para integrar a la cadena una mano de obra ya adiestrada. Entrevista a A. F., mando intermedio de la fábrica.

39 AFH, docs. IV, A, 1 y 8. Según recogió la prensa local, en mayo de 1965, en Imenasa se impartían, con reconocimiento oficial, las enseñanzas de Oficialía Industrial del Metal (con acceso a los 14 y 15 años de edad) e Iniciación Profesional (acceso a los 13 años) con las especializaciones de ajustador, matricero, fresador, tornero, calderero, forjador, cerrajero, soldador y chapista; es decir, unas especialidades fácilmente adaptables a las exigencias de la industria del motor. 
CUADRO 6

CUALIFICACIÓN DE LOS TRABAJADORES AGREMIADOS EN NAVARRA, 1955

\begin{tabular}{lrrrrrrrr}
\hline Sector & Especialistas & $\%$ & Aprendices & $\%$ & No Cualificados & $\%$ & Total & $\%$ \\
\hline Agua y Electricidad & 382 & 46 & 6 & 1 & 438 & 53 & 826 & 100 \\
Construcción & 1.572 & 45 & 118 & 3 & 1.840 & 52 & 3.530 & 100 \\
Papel & 528 & 91 & 51 & 9 & 0 & 0 & 579 & 100 \\
Curtido y calzado & 521 & 67 & 68 & 9 & 187 & 24 & 776 & 100 \\
Madera & 1.136 & 78 & 187 & 13 & 131 & 9 & 1.454 & 100 \\
Textil & 427 & 59 & 99 & 14 & 199 & 27 & 725 & 100 \\
Metal & $2.000^{*}$ & 80 & 349 & 14 & 143 & 6 & 2.492 & 100 \\
Química & 599 & 61 & 47 & 5 & 339 & 34 & 985 & 100 \\
\hline Total & $\mathbf{7 . 1 6 5}$ & $\mathbf{6 3}$ & $\mathbf{9 2 5}$ & $\mathbf{8}$ & $\mathbf{1 1 . 3 6 7}$ & $\mathbf{2 9}$ & $\mathbf{1 1 . 3 6 7}$ & $\mathbf{1 0 0}$ \\
\hline
\end{tabular}

$\left(^{*}\right)$ El número de obreros del metal era de 1.541, pero se redondeó para incluir a los mecánicos que trabajaban para el sector.

Fuentes: Censos de obreros por gremios en Ponencias del Primer Consejo Económico Sindical de Navarra (1954-55), original mecanografiado, colección particular.

Técnica Industrial de Pamplona. De tal modo que, a finales de la década de 1960, los informes internos de la Diputación estimaban que los cerca de 2.500 estudiantes navarros de FP representaban una tasa de escolaridad que duplicaba la del conjunto español (un 4 frente a un 2 por 100) ${ }^{40}$. En la misma dirección apuntan los datos del INE para el conjunto de las provincias españolas entre 1960 y 1970, que recoge el Cuadro 7 agregados por comunidades autónomas.

Los Planes de Desarrollo significaron en toda España un aumento en las cifras brutas y relativas de matriculados en el conjunto de la Formación Profesional Industrial, pero las trayectorias regionales evidencian historias diferenciadas. Habiendo alcanzado una posición intermedia en el conjunto del país hacia 1960, los datos de Navarra en la década siguiente confirman el esfuerzo inversor local en esa rama educativa al multiplicar por 2,5 el número de puestos de FP por cada 10.000 habitantes y, así, consolidar a esta comunidad entre las primeras. Junto a La Rioja — que partía de unos niveles reales muy bajos-, Navarra acumuló una ganancia que la distanciaba del resto de regiones, excepción hecha del País Vasco $^{41}$. No obstante, la comparación

40 AFH, doc. XXXII, C, 1; Rey Altuna (1965), p. 60.

41 Es cierto que el cociente demográfico suele favorecer estadísticamente a las regiones de poca población relativa. Habría que relacionarlo con el crecimiento de la población y los saldos demográficos. Las series históricas de capital humano presentan unos valores para Navarra por encima de la media española. Pérez, Goerlich y Mas (1996), pp. 265 y 269. 


\section{CUADRO 7}

MATRICULADOS EN FORMACIÓN PROFESIONAL INDUSTRIAL POR COMUNIDADES AUTÓNOMAS,

1960, 1965 Y 1970

\begin{tabular}{|c|c|c|c|c|c|c|c|c|}
\hline \multicolumn{3}{|c|}{1960} & \multicolumn{3}{|c|}{1965} & \multicolumn{3}{|c|}{1970} \\
\hline CC.AA. & (A) & (B) & CC.AA. & (A) & (B) & CC.AA. & (A) & (B) \\
\hline 1 País Vasco & 11.027 & 80,4 & 1 País Vasco & 11.386 & 83,0 & 1 País Vasco & 22.098 & 117,6 \\
\hline 2 Madrid & 11.223 & 43,1 & 2 La Rioja & 1.015 & 44,2 & 2 La Rioja & 2.117 & 89,8 \\
\hline 3 Asturias & 3.937 & 39,8 & 3 Navarra & 1.665 & 41,4 & 3 Asturias & 7.033 & 67,3 \\
\hline 4 Cataluña & 11.682 & 29,8 & 4 Madrid & 10.594 & 40,6 & 4 Navarra & 3.035 & 65,3 \\
\hline 5 Navarra & 1.193 & 29,7 & 5 Aragón & 4.412 & 39,9 & 5 Aragón & 5.878 & 51,0 \\
\hline 6 La Rioja & 656 & 28,5 & 6 Asturias & 3.770 & 38,1 & 6 Cataluña & 25.762 & 50,3 \\
\hline 7 Cantabria & 1.136 & 26,3 & 7 Castilla y León & 8.673 & 28,6 & 7 Cantabria & 2.285 & 48,9 \\
\hline 8 Castilla y León & 7.827 & 25,8 & 8 Cantabria & 1.229 & 28,4 & 8 Castilla y León & 13.438 & 48,5 \\
\hline 9 Aragón & 2.635 & 23,8 & 9 Murcia & 2.122 & 26,5 & 9 Madrid & 18.260 & 48,1 \\
\hline 10 Andalucía & 13.870 & 23,5 & 10 Andalucía & 14.933 & 25,3 & 10 Andalucía & 27.707 & 46,4 \\
\hline 11 Extremadura & 3.059 & 22,2 & 11 Cataluña & 8.995 & 22,9 & 11 Murcia & 3.174 & 38,1 \\
\hline 12 Valencia & 5.324 & 21,5 & 12 Valencia & 4.984 & 20,1 & 12 Galicia & 7.702 & 29,8 \\
\hline 13 Murcia & 1.409 & 17,6 & 13 Baleares & 872 & 19,7 & 13 Extremadura & 3.393 & 29,6 \\
\hline 14 Galicia & 4.462 & 17,1 & 14 Extremadura & 2.550 & 18,5 & 14 C.-La Mancha & 4.315 & 27,7 \\
\hline 15 Canarias & 1.529 & 16,2 & 15 Canarias & 1.627 & 17,2 & 15 Valencia & 8.459 & 27,5 \\
\hline 16 Baleares & 590 & 13,3 & 16 Galicia & 3.879 & 14,9 & 16 Canarias & 2.690 & 23,0 \\
\hline 17 C.-La Mancha & 2.080 & 11,6 & 17 C.-La Mancha & 2.599 & 14,5 & 17 Baleares & 1.128 & 20,2 \\
\hline
\end{tabular}

(A) Número de matriculados.

(B) Número de matriculados por cada 10.000 habitantes.

Fuentes: Instituto Nacional de Estadística (VV.AA.), Banco de Bilbao (1975) y Fundación BBV (1999).

de los ranking de matriculados en FP y de intensidad industrial muestra unos coeficientes de correlación de rangos elevados, mayores en 1970 que en $1960^{42}$. En 1960, de las seis regiones con mayor intensidad industrial, cuatro ocupaban también los primeros puestos en formación profesional. En 1970, de las seis regiones con mayor intensidad industrial, cinco se situaban en los primeros puestos en formación profe-

42 Los coeficientes de correlación de rangos de Spearman dan el siguiente resultado: matriculados FP/Intensidad industrial $1960=0,69(\mathrm{p} \leq 0,01)$; matriculados FP/Intensidad industrial $1970=0,76(\mathrm{p} \leq 0,01)$. Las fuentes son INE, Anuarios Estadísticos de España (VV.AA.) y Banco de Bilbao (1975). Para la intensidad industrial, Parejo (2001). Véase también Domínguez (2002), pp. 144-145. 
sional. La geografía del desarrollo económico regional estuvo relacionada con el esfuerzo realizado en la formación de capital humano.

Estas cifras agregadas no nos informan, sin embargo, de en qué medida la oferta educativa alivió la demanda de trabajadores mejor cualificados. Los datos de 1966, elaborados por el Ministerio de Trabajo para el conjunto del país, revelan que la situación estaba lejos de resolverse con eficacia. Abundaba el personal poco cualificado en todo tipo de industrias, afectando a la productividad y obligando a "las empresas no sólo a fomentar la asistencia a cursillos de capacitación, sino incluso a improvisar el aprendizaje en fábrica" ${ }^{\prime 3}$. Además, los aprendices de taller siguen sin poderse contabilizar. El estudio sectorial de cada región deberá tenerlo en cuenta. Al fin y al cabo, la demanda de factor trabajo — cualificado por métodos formales o informales- estará ligada tanto al grado de intensidad industrial de la región como al tipo de fábrica y especialización fabril ${ }^{44}$. En cualquier caso, Navarra había cosechado buenos resultados cualificando obreros aptos para la senda de crecimiento intensivo del sector metálico, en general, y de la automoción, en particular.

\section{Antes de Volkswagen: nacimiento, crisis y reconversión de la fábrica de coches}

Nada más acceder a la presidencia de la Diputación en abril de 1964, Félix Huarte Goñi puso en marcha un conjunto de planes de intervención pública para impulsar el desarrollo regional siguiendo el modelo de los Planes de Desarrollo gubernamentales. En su correspondencia privada confesaba tener "la obsesión de industrializar en lo posible a nuestra querida Navarra"45. No es extraño que se aprobara de inmediato un Programa de Promoción Industrial (PPI), que respondía al diagnóstico previo realizado por un equipo de economistas: combatir los saldos migratorios negativos, crear riqueza industrial de manera armónica en las distintas comarcas y reestructurar un sector secundario atomizado en exceso y poco cualificado en capital y mano de obra ${ }^{46}$. Confiando en que los incentivos forales resultasen más interesantes para los inversores

43 Consejo Económico Sindical Interprovincial del Norte (1969), pp. 18-19.

44 Así, en 1970, la escasez de mano de obra cualificada y de personal técnico era un problema menor en las grandes empresas; no obstante, "para las pequeñas industrias y las de escasa mecanización industrial supone una aguda y laboriosa cuestión a resolver". Consejo Económico Sindical de Navarra (1970), pp.105 y $138-140$.

45 AFH, Doc. 937. Mientras ocupó el cargo de presidente de la Diputación, la dirección de los negocios recayó en sus hijos y apenas se fundaron nuevas sociedades con domicilio navarro. Sin embargo, su voz fue determinante en las decisiones estratégicas del grupo. AFH, Doc. VI, 18.

$46 \quad$ Ardaiz (1980), I, pp. 24 y ss.; Consejo Económico Sindical de Navarra (1970), p. 78. 
foráneos que los ofertados en los polos de desarrollo promovidos por el Estado en pleno ciclo expansivo, ${ }^{47}$ Huarte y sus asesores desplegaron toda su capacidad de influencia para que grandes empresas se ubicasen en Navarra, justo en el momento en que un nuevo ensamblador de automóviles pugnaba por instalarse en España.

\subsection{La apuesta institucional por el metal y el automóvil}

Desde un punto de vista cuantitativo, el Programa de Promoción Industrial (PPI) dio prioridad a las empresas del metal y de la automoción y sus auxiliares (Cuadro 8). Se trataba del núcleo fabril que contenía mayor capacidad de arrastre en el proyecto difusor del cambio técnico acelerado, del empleo de capital humano mejor cualificado y, en definitiva, del conjunto de las pautas inherentes a la industrialización extensiva de los años sesenta. Nada menos que un 70 por 100 del capital público inyectado en el programa fue absorbido por esos dos sectores, con las empresas del motor en cabeza. Y en términos de empleo, las cifras validan una incidencia institucional muy directa en la consolidación de la senda de crecimiento industrial de la región: en 1972, nada menos que un 20 por 100 de la ocupación manufacturera lo aportaba un grupo de dieciséis grandes empresas ampliadas y mejoradas al calor del PPI. Más aún, en el sector del metal, hasta un 40 por 100 del empleo radicaba en nueve empresas acogidas al plan público de ayudas ${ }^{48}$.

A finales de 1964, la British Motor Corporation (BMC) firmó un acuerdo con Nueva Montaña Quijano (NMQ) para fabricar turismos Mini y diversos modelos de Austin y Morris. Eduardo Ruiz Huidobro, director gerente de NMQ, y G. W. Harriman, presidente de BMC, se comprometieron a iniciar la producción de "85.000 vehículos anuales" a partir de la segunda mitad de 1966, "con mayoría de componentes de fabricación española" y facilitando "ayuda económica completa"49. Las relaciones personales se mostraron tan necesarias como las disponibilidades de capital o los incentivos fiscales. Huarte y Huidobro se conocían a través de sus empresas y, en los meses de enero y febrero de 1965, la Diputación negoció el establecimiento de la fábrica en Pamplona, en disputa con Álava ${ }^{50}$. Las instituciones tuvieron claro que había que hacer un esfuerzo máximo dentro de sus posibilidades para atraer y retener

\footnotetext{
47 Sobre los incentivos fiscales, De la Torre (2005). En esas fechas, la presión fiscal en Navarra era claramente inferior a la de España. De la Torre y García-Zúñiga (2003) p. 124.

Cálculos propios a partir de De la Torre (2005).

Se preveía ensamblar "furgonetas, turismos, automóviles comerciales [...] de la muy amplia serie de BMC, con el fin de aumentar el número de modelos disponibles en el mercado español". Incluso se pensó en fabricar tractores agrícolas. Diario de Navarra, 4/03/1965 y 15/10/1965. También Catalan (2006), pp. 170-171. 


\section{CUADRO 8}

BALANCE DEL GASTO PÚBLICO EN LA INDUSTRIA DEL AUTOMÓVIL ACOGIDA AL PROGRAMA

DE PROMOCIÓN INDUSTRIAL DE NAVARRA, 1964-1969

(miles de pesetas corrientes)

\begin{tabular}{lcccc}
\hline & $\begin{array}{c}\text { Empresas } \\
\text { beneficiadas }\end{array}$ & Porcentajes & $\begin{array}{c}\text { Ayudas fiscales y } \\
\text { subvenciones liquidadas }\end{array}$ & Porcentajes \\
\hline Total & 196 & 100,0 & 1.104 .184 & 100,0 \\
\hline Metal & 42 & 21,4 & 308.686 & 28,0 \\
Automóvil & 18 & 9,2 & 471.620 & 42,7 \\
\hline Turismos & 1 & 0,5 & 148.952 & 13,5 \\
Auxiliares & 17 & 8,7 & 322.668 & 29,2 \\
\hline
\end{tabular}

Fuentes: Archivo del Departamento de Industria, Comercio y Turismo del Gobierno de Navarra (ADICT, en adelante), Cajas de Expedientes de Empresas, 1964-1969.

a un grupo con "solidez financiera, técnica y económica", así como "el elevado número de puestos de trabajo que se crean" y "su alto poder multiplicador". Se ampliaron generosamente las normas generales del PPI en favor de la fábrica de automóviles y las empresas subsidiarias. Ese carácter no formalizado de industria preferente se concretó, desde 1966, en "todos los beneficios posibles del PPI en su grado máximo y extraordinario": cesión gratuita de 46,6 hectáreas de polígono industrial con los servicios inherentes; una subvención del 50 por 100 del arancel por maquinaria importada y del 95 por 100 para la tecnología nacional; idéntica subvención de los gastos de constitución; aval institucional para un crédito de 200 millones de pesetas; exención durante quince años de diversas contribuciones; y una subvención directa equivalente a lo que se hubiese pagado por el Impuesto sobre el Tráfico de Empresas (ITE) en los diez primeros años de actividad ${ }^{51}$. La estrategia de lanzamiento se concretó en unas ayudas directas y fiscales de la hacienda foral a la planta de Landaben equivalentes al 13,5 por 100 del total destinado al PPI entre 1964 y 196952. El conjunto del sector del automóvil pudo así alcanzar casi plenamente los

51 AAN, Caja 2876/3, y ADICT, Exp. 179/68.

52 De la Torre (2005). Suponían el 6 por 100 del capital social de la empresa, sin incluir el valor de los terrenos cedidos gratuitamente en el polígono industrial. AUTHI era "la más significativa e importante de cuantas [industrias] se establecieron al amparo del PPI" y Huidobro fue homenajeado por la Diputación de Navarra. AFH, Doc. 959. Las subvenciones a fondo perdido sumaron el 75 por 100 de las ayudas forales, mientras la financiación de créditos representó un 12 por 100; el resto fue para importación de maquinaria y diversos gastos fiscales. ADICT, Cajas de Expedientes de Empresas, 1964-1977. 
objetivos de partida. Se trata de un ejemplo que induce a pensar que a las grandes empresas les interesaba, más que los incentivos fiscales, percibir ayudas a fondo perdido con las que cofinanciar las fases iniciales de instalación y las posteriores ampliaciones.

Con el tiempo, las ayudas se irían compensando con ingresos tributarios para las arcas forales derivados, directa o indirectamente - a través de la creación de empleo y riqueza-, de la fábrica. El director de la Hacienda provincial se frotaba las manos al pensar en las ventas de 20.000 vehículos en la etapa inicial que pagarían el ITE "íntegramente a la Diputación"53; a lo que habría que añadir el consumo y los impuestos de 1.000 empleos directos de AUTHI en 1970 y de 1.650 en 1973 — sólo la empresa del INI Potasas de Navarra empleaba más trabajadores en la provincia- ${ }^{54}$. Aplicada esta lógica a la totalidad de empresas y trabajadores, cabría subrayar la búsqueda de ese círculo virtuoso del crecimiento económico regional.

\subsection{La quiebra de AUTHI y la entrada de SEAT}

Sin embargo, la andadura de AUTHI afrontó complicaciones muy pronto. En abril de 1967 comenzó la producción en serie de 450 turismos diarios, con motores que procedían de NMQ y con los principales componentes suministrados por Urra (frenos) e Imenasa (direcciones) ${ }^{55}$. Pero ganar cuota de mercado resultó difícil, sobre todo porque en sus primeros años de vida fue "la única fábrica de automóviles en España que carecía del respaldo económico de la casa licencitaria"; por ello, "la lucha" de "cuatro colosos extranjeros frente a un verdadero David español de muy limitados recursos financieros" fue "muy desigual". Eran las palabras del marqués de Huidobro a Félix Huarte explicándole, en julio de 1969, la entrada de British Leyland (BL) como socio tecnológico y financiero en 1970, la solución al dilema "consolidar la obra comenzada o renunciar". En concreto, BL adquiriría el 50 por 100 de NMQ, quedando la gestión en manos británicas y siendo relegado el presidente y fundador Huidobro $^{56}$. Así, AUTHI pasaba de un modesto capital fundacional de 20 millones de

53 AAN, Hacienda, Caja 2876/3, "Informe del Director de Hacienda".

$54 \quad$ Las cifras de empleo en Iriarte (1995), pp. 78 y 176. Las plantillas de Pamplona, Santander y Manresa sumaban 4.500 empleos directos en 1974, sin contar los de la red de talleres y concesionarios de todo el país y los de la industria auxiliar, según el Jurado de Empresa de AUTHI, Diario de Navarra, 13/12/1974.

55 ADICT, Exp.29/76; y Consejo Económico Sindical de Navarra (1970), p. 90. La producción en serie no arrancó hasta principios de 1967, pero el primer prototipo ensamblado en Landaben se exhibió el 1 de octubre de 1966 ante la prensa local y nacional. En 1969 se alcanzaba la producción anual de 20.000 vehículos. AFH, Doc. 952. 
pesetas a otro de cerca de 3.000 millones (fruto de las aportaciones de NMQ, BL y una gran emisión de obligaciones) ${ }^{57}$, con el objetivo de lanzar en serie el famoso modelo "Mini".

Sin embargo, las ventajas de explotar un mercado protegido, con una mano de obra barata y relativamente bien cualificada, no fueron suficientes para que AUTHI lograse ser una firma competitiva en el panorama español. La inversión de capital en grandes cantidades y las ayudas públicas permitieron un aumento del volumen de ventas entre 1970 y 1973, que duplicó el del trienio precedente. No obstante, las pérdidas acumuladas - explicadas en parte por los conflictos laborales habidos de 1970 a $1974^{58}$ y un incendio del almacén de componentes de guarnecido en octubre de ese último año- pusieron en peligro a la empresa y mostraron las debilidades del naciente sector automovilístico español. A las dificultades del mercado español se añadían las de una coyuntura internacional adversa para la industria del automóvil, caracterizada por el fin de la Edad Dorada y el primer shock petrolífero: en Francia, el gobierno tuvo que auxiliar financieramente a Citroën; en Italia, la FIAT acumulaba stocks invendidos; y en Gran Bretaña, Ford y Chrysler anunciaban despidos masivos, mientras British Leyland parecía abocada a la nacionalización ${ }^{59}$, con lo que peligraba la viabilidad de la factoría navarra.

En el verano de 1973, unas pérdidas de 1.267 millones de pesetas revelaban una situación patrimonial tan deteriorada que exigía una disminución del capital social. Ello se hizo reduciendo el valor nominal de las acciones en un 90 por 100, lo que fue seguido por un nuevo desembolso de 2.259 millones de capital por British Leyland a través de los bancos Central y Urquijo. Con todo, la empresa quedó abocada a la quiebra. El procurador navarro en Cortes, Ezponda, calificaba la situación de "insostenible" y "en peligro de liquidación", puesto que la empresa "arrastra desde el principio unas pérdidas enormes", equivalentes, a finales de 1974, "al 70 por 100 del patrimonio, lo que legalmente obliga a AUTHI a la disolución de la Sociedad, salvo reposición del nuevo capital". El índice de penetración en el mercado descendía del 6,2 a 2,7, algunos directivos abandonaban la empresa y el desánimo cundía entre los trabajadores y distribuidores ${ }^{60}$. En este escenario, los ingleses, propietarios de un 98

57 En junio de 1970 se registraba la ampliación en 1.387 millones de pesetas, de los que NMQ aportaba la mitad en forma de bienes — exactamente, la fábrica de motores de Corrales de Buelna (Cantabria) — y 229 millones en dinero, mientras que BL transfería el importe de su cuota en libras esterlinas a través del Banco de Santander. Un mes después, los accionistas aprobaban la emisión de obligaciones por valor de 1.500 millones de pesetas. RMN, Hoja 2288.

$58 \quad$ Iriarte (1995), pp. 74-75 y 152.

59 La empresa multinacional británica, con intereses financieros y plantas de ensamblaje en Europa y África del Sur, empleaba en total a 160.000 trabajadores. Diario de Navarra, 7 y 13/12/1974.

60 RMN, Hoja 2288; Diario de Navarra, 13/12/1974. 
por 100 de las acciones, iniciaron conversaciones con General Motors para venderles su negocio en España, mientras el Ministerio de Industria parecía inclinarse por un reparto entre SEAT, FASA-Renault y Citroën ${ }^{61}$. Cualquiera de las dos alternativas requería el acuerdo del Gobierno y reabría el viejo debate de reservar el mercado a las empresas nacionales o permitir nuevas entradas de capital extranjero ${ }^{62}$, sólo que ahora en un contexto de frenazo en seco del ciclo expansivo. AUTHI, finalmente, suspendía pagos en febrero de 1975.

En definitiva, desde la estricta perspectiva empresarial del corto plazo, la fase de creación de la fábrica de montaje de coches se saldaba con un sonoro fracaso. El cierre mostraba que la empresa había sido incapaz de competir siquiera en condiciones de mercado reservado. Del total de la producción española de coches, AUTHI nunca aportó más del 7 por $100^{63}$, cifra no despreciable pero lograda con unos costes excesivamente altos y sobre la que pesaba un socio multinacional con problemas que, además, pretendió colocar en el mercado hispano modelos que, ya cumplido su ciclo vital, rozaban la obsolescencia y resultaban más caros que los de sus potenciales adversarios ${ }^{64}$. No obstante, desde una perspectiva global, esta experiencia negativa dejaba un embrión que, tras sufrir un proceso de reconversión y ajuste bajo el paraguas del Estado, permitiría que Navarra siguiese contando en la industria automovilística.

El ciclo expansivo había mostrado a la Administración Pública las virtudes de un modelo interventor que era capaz de contribuir al establecimiento de grandes empresas, generar externalidades positivas en términos de empleo y transformación del tejido productivo y, además, mejorar la recaudación fiscal. El estallido de la crisis industrial de los años setenta obligó a reconducir esa política, pero sin abandonar a su suerte a los subsectores de vanguardia. Los cierres de empresas y el crecimiento del desempleo empujaron al alza las ayudas públicas en general,

61 Si no resulta extraño que la matriz inglesa estuviese dispuesta a liquidar la empresa, la propuesta del consorcio SEAT-FASA-Citroën hacía presagiar la nacionalización de las pérdidas a través del INI. El análisis del procurador Ezponda no parece descabellado: la venta de acciones a los tres grandes productores nacionales trataba de "eliminar a un competidor"; los 3.600 millones de pesetas convenidos eran "nada más y nada menos que divisas a pagar a los ingleses" en plena crisis; la venta a General Motors significaría justamente lo contrario; $y$, además, si se optaba por el consorcio español parte del dinero vendría del crédito oficial, en beneficio de unas empresas y en detrimento de otras. RMN, Hoja 2288; Diario de Navarra, 13/12/1974; Catalan (2006), pp. 174 y 182.

62 Los trabajadores de AUTHI lo resumían con claridad: "No nos parece oportuno que se invoque ahora el peligro de hipotecar la industria nacional por el capital extranjero a costa de los trabajadores, cuando la industria del automóvil, amén de otros muchos sectores industriales, tiene fuerte participación extranjera". Carta dirigida al presidente del gobierno, Diario de Navarra, 14/12/1974.

63 González de la Fe (2001), p. 10.

64 Sobre los riesgos de un socio licenciatario en apuros, véase el ejemplo de Barreiros en García Ruiz y Santos (2001), pp. 329-331. 


\section{CUADRO 9}

BALANCE DEL GASTO PÚBLICO EN LA INDUSTRIA DEL AUTOMÓVIL ACOGIDA AL PROGRAMA

DE PROMOCIÓN INDUSTRIAL DE NAVARRA, 1970-1977

(miles de pesetas corrientes)

\begin{tabular}{lcccc}
\hline & $\begin{array}{c}\text { Empresas } \\
\text { beneficiadas }\end{array}$ & Porcentajes & $\begin{array}{c}\text { Ayudas fiscales y } \\
\text { subvenciones liquidadas }\end{array}$ & Porcentajes \\
\hline Total & 105 & 100,0 & 3.245 .964 & 100,0 \\
\hline Metal & 26 & 24,8 & 399.534 & 12,3 \\
Automóvil & 13 & 12,4 & 1.367 .081 & 42,1 \\
\hline Turismos & 1 & 0,9 & 1.055 .009 & 32,5 \\
Auxiliares & 12 & 11,5 & 312.072 & 9,6 \\
\hline
\end{tabular}

Fuentes: ADICT, Cajas de Expedientes de Empresas, 1970-1977.

pero el sector de la automoción fue objeto de un trato preferencial, convirtiéndose, en virtud de ello, en una excepción dentro de un panorama fabril crítico. Mientras que el conjunto de la industria navarra recibió dinero público de la Hacienda foral por debajo de lo acordado - espejo del deterioro de las expectativas y de la incapacidad de las empresas para lanzar proyectos- y el sector del metal se desplomó, el automóvil y sus derivados registraron un resultado netamente positivo (Cuadro 9). En los años setenta la automoción se reforzó como sector estrella para los responsables políticos de Navarra, con la planta de ensamblaje en primerísimo término, lo que muestra que había sido escogida como rama productiva sobre la que hacer descansar la salida de la crisis, aprovechando el entramado más dinámico de la industrialización gestada en la década del desarrollismo. Lo que ocurría en Navarra tenía su correlato en el conjunto de España, pues, tras los acuerdos con Ford ${ }^{65}$, la industria automovilística se había convertido de modo definitivo en una manufactura preferente.

Una de las claves para que SEAT - firma controlada por el INI y octavo fabricante europeo en esas fechas - ${ }^{66}$ adquiriese en 1976 las instalaciones de AUTHI fue la interpretación tan flexible que se estaba dispuesto a hacer del PPI de Navarra. Los acuerdos entre la nueva propietaria y la Diputación respondieron al contexto recesivo. Las autoridades navarras ofrecieron un trato fiscal preferente y un conjunto de ayudas directas a cambio del compromiso de SEAT de dar prioridad a los trabaja-

65 Catalan (2000) y García Ruiz (2003).

66 González de la Fe (2001). 
dores y empresas de la región, sobre un trasfondo de conflictividad social y política que estaba condicionando el papel subsidiario del Estado y de la Diputación de Navarra durante la transición de la dictadura a la democracia.

El convenio de agosto de 1976 incluía la obligación de "contratar a todo el personal que ha prestado servicios en AUTHI" y de que los nuevos empleos se destinasen a "residentes en Navarra [y en particular a] aquéllos que hubiesen quedado en situación de paro forzoso a causa de expedientes de crisis de empresas navarras"; además, había que "dar preferencia a los fabricantes navarros de materias primas y productos manufacturados". Así, SEAT se hacía con la planta ensambladora de Landaben por 1.100 millones de pesetas, un precio más que razonable si atendemos al valor de los activos de la empresa. En febrero de 1977 se reformuló el convenio para adaptarlo a las necesidades de la factoría de Barcelona y fijar la secuencia de ayudas públicas a los planes quinquenales de inversión para lanzar el modelo "124", al que se sumarían los "Lancia" y "Panda". En manos de sus nuevos gestores, la fábrica de coches levantó pronto el vuelo en una estrategia claramente orientada a la conquista del mercado internacional. De hecho, los 3.671 millones de pesetas en inversiones previstas para el quinquenio 1978-1982 se triplicaron —en febrero de 1980 se preveía unos 11.720 millones-, lo que condujo a renegociar los acuerdos entre SEAT y la Diputación ${ }^{67}$. Hay que subrayar que la reconversión y relanzamiento de la fábrica navarra, en plena transición a la democracia, contó con el apoyo de las instituciones de la región, con independencia de que en esos años los representantes políticos del franquismo fuesen sustituidos por otros que eran miembros de partidos de izquierda ${ }^{68}$. Existió unanimidad entre los gestores públicos a la hora de salvar un sector que, en caso de desaparecer, agravaría dramáticamente la crisis industrial.

La entrada de SEAT permitió la rápida recuperación de la actividad, orientada primero al mercado español y luego, desde 1979, hacia la exportación. En ese año, ya casi un 15 por 100 de los turismos se colocaron en el mercado internacional, pero las previsiones para 1981-1985 estimaban que el 44,9 por 100 de la cifra de ventas global, 160.200 millones de pesetas, tuviese ese origen ${ }^{69}$. La integración paulatina de SEAT en el consorcio Volkswagen en los años ochenta confirmaría las excelentes expectativas $^{70}$.

$67 \quad$ ADICT, Exp. 29/76.

68 El convenio de 1976 fue negociado por la última Diputación franquista y el de 1980 por un diputado responsable de la cartera de Industria, que había sido elegido en una candidatura de la izquierda nacionalista.

69 ADICT, Exp. 29/76.

70 Lagendijk (1995) y Fábrica Navarra de Automóviles (FNASA, 1994). 
CUADRO 10

INGRESOS DE SEAT NAVARRA Y SUBVENCIONES PÚBLICAS, 1976-1979

(millones de pesetas)

\begin{tabular}{lrrrrrr}
\hline & $\mathbf{1 9 7 6}$ & $\mathbf{1 9 7 7}$ & $\mathbf{1 9 7 8}$ & $\mathbf{1 9 7 9}$ & Total & $\begin{array}{c}\text { Porcentaje } \\
\text { del total }\end{array}$ \\
\hline Ventas totales & 4.206 & 7.938 & 9.990 & 10.705 & 32.839 & 100,0 \\
\hline Ventas nacionales & 4.203 & 7.933 & 9.851 & 9.100 & 31.087 & 94,6 \\
Ventas en el extranjero & 3 & 5 & 139 & 1.605 & 1.752 & 5,4 \\
\hline Ingresos brutos ITE (a) & 100 & 190 & 238 & 239 & 767 & \\
Subvención ventas (b) & 22 & 42 & 53 & 57 & 174 & \\
Subvención directa (c) & & & & & $300 / 1.100$ & \\
\hline
\end{tabular}

(a) De los Ingresos Brutos ITE, la Diputación debía entregar a la Hacienda del Estado el 33,25 por 100 en concepto de compensación por impuestos indirectos; un porcentaje retornaba a los ayuntamientos por las ventas nacionales.

(b) Se fijó en un 0,53 por 100 del valor final de cada turismo vendido.

(c) Equivalía al 10 por 100 de las inversiones previstas.

Fuentes: ADICT, Exp. 29/76.

\section{Conclusiones}

La historia de la industria del automóvil a escala regional permite abordar con cierto grado de complementariedad los dos ejes del debate - problemas de oferta, problemas de demanda - en torno al nacimiento y consolidación de una de las ramas fabriles que más impulsó la industrialización en la España de Franco. En los años cincuenta se esgrimieron diversos argumentos para justificar la intervención, que fueron revestidos con una cierta lógica de mercado: del lado de la oferta, se decía que la industria auxiliar estaba sobrecargada, sus métodos eran ineficientes y excesivos los precios; del lado de la demanda, se aducía que las ventas serían escasas en un país de renta baja. No obstante, las mismas fuentes oficiales revelan que la viabilidad de los proyectos estuvo condicionada por las relaciones de poder. Políticos, técnicos, ministros - y hasta el Jefe del Estado- y empresarios, con mayor o menor nivel de acceso a instancias gubernamentales, dirimieron una lucha sorda entre la racionalidad económica y el poder político para inclinar la balanza a favor de unos y arrinconar a otros. Finalmente, la fuerte expansión de los años sesenta terminó por desvirtuar el discurso intervencionista anterior.

En el caso de Navarra, la concurrencia fallida de una empresa francesa y de otra nacional ejemplifica cómo las decisiones políticas fueron tan determinantes como las del mercado. No sólo se trataba de un conflicto entre el Estado, entendido en sentido amplio, y los empresarios privados, sino también entre empresas ya situadas, que pre- 
sionaban para proteger su negocio, y empresas emergentes que detectaban y buscaban aprovechar las oportunidades. Los fallos de oferta atribuidos por el Ministerio a la industria auxiliar no parecían tan graves como se quería hacer ver. Hay que tener en cuenta que las apuestas se hacían en un contexto regional próximo a uno de los espacios con mayor nivel relativo de industrialización, el País Vasco, que, además, se hallaba en un acelerado proceso inversor durante ese período. Por otra parte, ya desde mediados de los años cincuenta, Navarra contó con un grupo de empresarios dispuestos a fabricar los bienes intermedios que precisaba la automoción promovida por el Estado y a adiestrar a la mano de obra procedente del éxodo rural. La estrategia y la capacidad de respuesta del incipiente grupo industrial de Félix Huarte lo ratifican.

En el origen, las industrias auxiliares del motor precedieron a la planta de ensamblaje. Los pequeños talleres y las secciones de algunas fábricas metalúrgicas fueron capaces en poco tiempo de abastecer de componentes a las plantas de material de transporte; más aún, configuraron el núcleo adecuado para articular una respuesta inmediata en el momento en que la fábrica de turismos de Pamplona se convirtió en realidad. El problema es que esta fábrica fue sostenida por un socio tecnológico europeo en declive y entró en funcionamiento en una coyuntura económica complicada. Pronto se revelarían problemas financieros graves por la dificultad de AUTHI para consolidarse en el mercado español, que no pudieron ser debidamente afrontados por la profunda crisis de British Leyland en la Inglaterra de los primeros años setenta.

En un contexto tan adverso, la acción institucional, en un maridaje estrecho entre lo público y lo privado, resultó clave para que la iniciativa empresarial de la región pudiese aprovechar la oportunidad de negocio que se presentaba en un mercado emergente y con futuro incierto a largo plazo. Las ayudas brindadas por la Diputación de Navarra colaboraron al despegue inicial del sector y, luego, a resolver su crisis y a su consolidación - y en lo que el papel del INI a través de SEAT fue una de las claves de continuidad-. Incentivos fiscales y subvenciones directas fueron otorgados por la institución que en Navarra tenía la capacidad de asignarlos y que estuvo siempre bien conectada con el principal grupo de empresarios de la región. Intervención pública y beneficios privados concurrieron a favor del desarrollo regional mostrándose perfectamente compatibles.

\section{Bibliografía}

ALÁEZ, Ricardo, y ERRO, Amaia (2006): “The Automotive Industry in the 'Old Periphery' of the European Union: regional input linkages of Volkswagen Navarra SA", Tijdschrift loor Economische en Sociale Geografie, 97, 4, pp. 377-388.

ARDAIZ, Iosu (1980): Navarra, elementos para su estudio regional, Pamplona, Eusko Ikaskuntza. 
BANCO DE BILBAO (1975): Renta nacional de España y su distribución provincial. Serie homogénea (1955-1974), Bilbao, Banco de Bilbao.

CARMONA, Xoan (2003): "Da sardiña ao automóbil: unhas notas sobre a industria viguesa do século XX", en VÁZQUEZ-VICENTE, Xosé (dir.), Vigo, economía e sociedade, Vigo, Xerais, pp. 35-54.

CATALAN, Jordi (2000): "La creación de la ventaja comparativa en la industria automovilística española, 1898-1996", Revista de Historia Industrial, 18, pp. 113-155.

-(2006): "La SEAT del desarrollo, 1948-1972", Revista de Historia Industrial, 30, pp. 143-196.

CONSEJO ECONÓMICO SINDICAL DE NAVARRA (1970): Estructura y posibilidades de desarrollo económico de la provincia de Navarra, Pamplona, CESN.

CONSEJO ECONÓMICO SINDICAL INTERPROVINCIAL DEL NORTE (1969): Promoción Industrial. Preámbulo y conclusiones, Madrid, original mecanografiado.

CRAFTS, Nicholas, y TONIOLO, Gianni (eds.) (1996): Economic growth in Europe since 1945, Cambridge, Cambridge University Press.

DE LA TORRE, Joseba (2005): “Instituciones, empresarios y mercado. La industrialización de Navarra bajo el franquismo", Revista de Historia Industrial, 27, pp. 121-161.

DE LA TORRE, Joseba, y GARCÍA-ZÚÑIGA, Mario (2003): "Política presupuestaria y crecimiento económico en Navarra, 1890-1970", Revista de Historia Económica, XXI, 1, pp. 113-145.

DOMÍNGUEZ, Rafael (2002): La riqueza de las regiones. Las desigualdades económicas regionales en España, 1700-2000, Madrid, Alianza.

FÁBRICA NAVARRA DE AUTOMÓVILES, S.A. (1994): Yo lancé el A03, Pamplona, FNASA.

FUNDACIÓN BBV (1999): Renta Nacional de España y su distribución homogénea. Años 1955 a 1993 y avances 1994 a 1997, 2 vols., Madrid, Fundación BBV.

GARCÍA RUIZ, José Luis (2001): “Evolución de la industria automovilística española, 1946-1999: una perspectiva comparada", Revista de Historia Industrial, 19-20, pp. 133-164.

GARCÍA RUIZ, José Luis, (dir.) (2003): Sobre ruedas. Una historia crítica de la industria del automóvil en España, Madrid, Síntesis.

GARCÍA RUIZ, José Luis, y SANTOS REDONDO, Manuel (2001): ¡Es un motor español! Historia empresarial de Barreiros, Madrid, Síntesis/Fundación Eduardo Barreiros.

GARRUÉS, Josean (2006): “Del lento despertar de la empresa industrial navarra y el acelerado tránsito al capitalismo gerencial", GARCÍA RUIZ, José Luis, y MANERA, Carles (dirs.), Historia empresarial de España. Un enfoque regional en profundidad, Madrid, LID, pp.173-210.

GONZÁLEZ DE LA FE, Pedro (2001): SEAT: fundación, desarrollo y privatización de una empresa automovilística en España, Documento de Trabajo 2001/1, Madrid, Fundación Empresa Pública. 
HAYTER, Roger (2004): The Dynamics of Industrial Location: The Factory, the Firm and the Production System, Burnaby, Simon Fraser University.

INSTITUTO NACIONAL DE ESTADÍSTICA (VV.AA.): Anuario Estadístico de España, Madrid, INE.

IRIARTE, José Vicente (1995): Movimiento obrero en Navarra (1967-1977). Organización y conflictividad, Pamplona, Gobierno de Navarra.

JEREZ, Miguel (1982): Élites políticas y centros de extracción en España, 1938-1957, Madrid, Centro de Investigaciones Sociológicas.

KRUGMAN, Paul (1999): El retorno de la economía de la depresión, Barcelona, Crítica.

LAGENDIJK, Arnoud (1995): “The Foreign Takeover of the Spanish Automobile Industry: A Growth Analysis of Internationalization", Regional Studies, 29, pp. 381-393.

LLOPIS, Enrique, y FERNÁNDEZ, Rafael (1998): “Las industrias manufactureras regionales en la época del desarrollismo. Un nuevo análisis de localización y convergencia", Revista de Historia Industrial, 13, pp. 113-145.

LOUBET, Jean-Louis (1996): Automobiles Peugeot: une réussite industrielle, 1945-1974, París, Economica.

MUÑOZ, Juan (1969): El poder de la banca en España, Madrid, ZYX.

NADAL, Jordi, y TAFUNELL, Xavier (1992): Sant Martí de Provençals, pulmó industrial de Barcelona (1847-1992), Barcelona, Columna.

PAREDES, Javier (comp.) (1995): Félix Huarte. Fuentes Históricas, Madrid, Rialp.

PAREDES, Javier (1997): Félix Huarte, 1896-1971: un luchador enamorado de Navarra, Barcelona, Ariel.

PAREJO, Antonio (2001): "Industrialización, desindustrialización y nueva industrialización de las regiones españolas (1950-2000). Un enfoque desde la historia económica", Revista de Historia Industrial, 19-20, pp. 15-75.

PÉREZ, Francisco; GOERLICH, Francisco José; y MAS, Matilde (1996): Capitalización y crecimiento en España y sus regiones, 1955-1995, Madrid, Fundación BBV.

REY ALTUNA, Luis (1965): La enseñanza en Navarra. Situación y perspectivas. Pamplona, Diputación Foral de Navarra.

RODWIN, Lloyd, y SAZANAMI, Hidehiko (eds.) (1991): Industrial Change and Regional Economic Transformation. The Experience of Western Europe, London, Harper Collins.

SAN ROMÁN, Elena (1999): Ejército e industria: el nacimiento del INI, Barcelona, Crítica.

SINDICATO NACIONAL DEL METAL (1963): El Sindicato del Metal, evolución y perspectiva de sus industrias, Madrid, Consejo Económico Sindical Nacional.

VALDALISO, Jesús María (2002): “Grupos empresariales y desarrollo económico en España en el siglo XX: los negocios de la familia Aznar (c. 1937-c. 1983)", Revista de Historia Económica, XX, 3, pp. 577-624. 